\title{
Hubungan Motivasi Kerja, Karakteristik Individu dan Kompensasi terhadap Disiplin Kerja Perawat Rumah Sakit Cikunir Bekasi Tahun 2018
}

\author{
Dini Rahmawati Permana \\ Program Studi Manajemen Administrasi Rumah Sakit \\ Universitas Respati Indonesia \\ Email: dinirahmawati333@gmail.com
}

\begin{abstract}
Discipline is a function of operational human resources management the most important because the better the working discipline employees the better performance is achieved. Factor affecting the discipline of work i.e. the motivation of working nurses to increase productivity, the characteristics of the individuals belonging to each nurse, as well as the existence of the application of the compensation is good for the welfare of nurses. This research aims to look at the description of the work discipline Hospitals Cikunir bekasi as well as find out how relationships work, the characteristics of individual motivation and compensation against the discipline of nursing work in a hospital Cikunir Bekasi. This research uses a quantitative approach with methods "Cross Sectional". The research sample is all over the nurses as much as 30 people were taken with the total sampling method. Univariate analysis done subsequent to see frequency distribution, bivariat analysis using Pearson Correlation and multivariate analysis using multiple linear regression. The test results showed that the bivariate variables work motivation, compensation and individual characteristics have a significant relationship against the discipline of work. Whereas, in multivariate test of variables of individual characteristics, work motivation and compensation the most dominant effect significantly to the discipline of work i.e. the individual characteristics of the variable with a value of 0.0020 .546 Beta with significance. To increase work discipline nurses RS Cikunir Bekasi, required the effort of increasing internal and external training of nurses and nursing career, improving the motivation of working nurses by providing a reward or promotion position in accordance with performance assessment the nurse.
\end{abstract}

Keywords:

Work motivation, individual characteristics, compensation, work discipline

\section{PENDAHULUAN}

Pelayanan rumah sakit sebagai industri jasa merupakan bentuk upaya pelayanan kesehatan yang bersifat sosio ekonomi yaitu suatu usaha yang walaupun bersifat sosial, tetapi diusahakan agar bisa memperoleh keuntungan dengan cara pengelolaan yang profesional. Rumah sakit merupakan institusi yang bersifat kompleks serta bersifat organisasi yang beragam. Untuk itu, diperlukan bantuk manajemen sistem pelayanan yang modern untuk setiap bidang kerja atau unit kerja sehingga sistem pelayanan pada setiap rumah sakit perlu ditinjau kembali untuk mengantisipasi persaingan di tingkat dunia.

Sumber daya manusia terbanyak yang berinteraksi secara langsung dengan pasien adalah perawat, sehingga kualitas pelayanan yang dilaksanakan oleh perawat dapat dinilai sebagai salah satu indikator baik atau buruknya kualitas pelayanan di rumah sakit (Aditama, 2000). Tenaga keperawatan yang mempunyai kedudukan penting dalam menghasilkan kualitas pelayanan kesehatan di rumah sakit, karena pelayanan yang diberikannya berdasarkan pendekatan bio-psiko-sosial-spiritual merupakan pelayanan yang unik dilaksanakan selama 24 jam dan berkesinambungan merupakan kelebihan tersendiri dibanding pelayanan lainnya (Departemen Kesehatan RI, 2001).

Kesadaran akan pentingnya keberadaan SDM yang berkualitas, dalam hal ini perawat, perlu ditindaklanjuti dengan berbagai strategi yang dapat meningkatkan kualitas perawat. Salah satu yang diukur dalam kualitas kinerja perawat adalah masalah kedisiplinan. Disiplin adalah suatu proses yang dapat menumbuhkan perasaan seseorang untuk mempertahankan dan meningkatkan tujuan organisasi secara objektif, melalui kepatuhannya menjalankan peraturan organisasi. Menurut Soejono dalam Kusumawarni (2007), disiplin kerja karyawan dapat dikatakan baik apabila memenuhi syarat, diantaranya datang dan pulang sesuai dengan peraturan, tertib, berpakaian rapi dan berartibut dinas lengkap, serta melaporkan jika tidak masuk kerja. Menurut Hasibuan (2005) tingkat disiplin kerja seorang pegawai dapat dipengaruhi oleh beberapa hal yang salah satunya adalah motivasi kerja dari pegawai itu sendiri, sehingga pegawai yang memiliki motivasi tinggi tentunya akan memiliki disiplin yang tinggi pula. Motivasi menjadikan penting karena dengan motivasi diharapkan setiap individu bersedia bekerja keras, disiplin dalam menaati berbagai kebijakan dan peraturan, serta antusias untuk mencapai produktivitas yang tinggi. Menurut Hasibuan (2005), salah satu tujuan pemebrian motivasi adalah untuk meningkat kedisiplinan dan menurunkan tingkat absensi karyawan. Kompensasi dalam organisasi harus dihubungkan dengan tujuan dan strategis organisasi. Kompensasi juga membuat kesimbangan antara keuntungan dan biaya. 
Menyadari betapa pentingnya karyawan sebagai sumber daya manusia sebagai aset yang berharga, maka perlu diperhatikannya pemberian kompensasi pemberian kompensasi sebagai imbalan yang layak untuk sebuah penghargaan terhadap apa yang telah dikerjakan para karyawan.

RS Cikunir Bekasi dipilih karena merupakan salah satu jaringan penyediaan jasa layanan kesehatan di kota Bekasi Jawa Barat. RS Cikunir Bekasi mengkhususkan diri dalam bidang pelayanan spesialistik kebidanan, penyakit kandungan, dan kesehatan anak dan penyakit - penyakit lainnya.

Pada hasil observasi dan wawancara didapatkan bahwa jumlah keterlambatan dan pulang lebih awal masih terlihat belum mematuhi peraturan - peraturan yang berkaitan dengan kedisiplinan, sedangkan untuk tingkat keterlambatan karyawan RS Cikunir yang didapt melalui HRD di bulan januari sampai juni 2018 yaitu pada perawat tingkat keterlambatan $20 \%$ dan ketidakhadiran 10\%. Masih ada pula karyawan yang masih lalai terhadap absensi sidik jari. Hal ini dapat membuat kegiatan operasional tidak berjalan dengan baik.

\section{METODE PENELITIAN \\ Rancangan}

Penelitian ini adalah penelitian kuantitatif dengan pendekatan Cross Sectional Study. Sehingga pengumpulan data dilakukan dalam waktu yang bersamaan, dimana setiap subjek hanya diteliti satu kali.

\section{Waktu dan Lokasi Penelitian}

Penelitian ini dilakukan di bulan Agustus 2018 di RS Cikunir Bekasi

\section{Populasi dan Sampel}

Populasi penelitian adalah seluruh perawat yang bekerja di RS Cikunir Bekasi yang berjumlah 30 orang.

\section{Instrumen Penelitian}

Penelitian ini menggunakan kuisioner yang diisi oleh seluruh perawat dengan skala Ordinal dan menggunakan form penilaian disiplin kerja yang diisi oleh atasan.

\section{Validitas \& Reliabilitas}

Instrumen penelitian sebelum diedarkan dilakukan uji validitas dan reliabilitas di RS lain dengan responden 30 perawat dan hasilnya adalah semua valid dan reliabel.

\section{Sumber \& Jenis Data Penelitian}

Data primer dan sekunder

\section{Metode \& Tehnik Pengumpulan Data}

Menyebarkan kuisioner, pengisian form penilaian disiplin kerja perawat yang diisi oleh atasan dan dikumpulkan ke peneliti.

\section{Pengumpulan dan Analisa Data}

Editing, coding, tabulating dengan melakukan uji statistik univariat dan bivariat dengan uji korelasi Pearson dan multivariate dengan Analisis regresi linier berganda

\section{HASIL DAN PEMBAHASAN \\ Gambaran Rumah Sakit}

Rumah Sakit Umum Cikunir Bekasi berdiri sejak 2014, ijin operasional RS Cikunir terbit pada tanggal 16 Maret 2015. RS Cikunir adalah RS tipe D dengan kapasitas 64 tempat tidur, 8 orang dokter spesialis, 6 orang dokter umum, 1 orang dokter gigi, 30 perawat, dan 24 orang penunjang medis. Tenaga keperawatan di RS Cikunir adalah profesi terbanyakk dari seluruh karyawan. Adapun penempatan perawat adalah 6 orang di rawat jalan, 5 orang di IGD, 4 orang di kamar operasi, 3 orang di HCU, 4 orang di ruang rawat inap lantai 4 dan 4 orang di ruang rawat inap lantai 5.

\section{Karakteristik Individu \\ Karakteristik Responden Berdasarkan Jenis Kelamin}

Jumlah responden terbanyak adalah perempuan sebanyak $80 \%$

\section{Karakteristik Responden Berdasarkan kisaran usia \\ Jumlah responden terbanyak adalah pada kelompok usia 26-30 tahun sebanyak $40 \%$.}

\section{Karakteristik Responden Berdasarkan Tingkat Pendidikan} Jumlah responden terbanyak adalah dengan tingkat pendidikan D3 sebanyak $77 \%$.

\section{Karakteristik Responden Berdasarkan Lamanya Kerja Jumlah responden terbanyak sudah} bekerja selama 6 bulan- 1 tahun (59\%).

\section{Karakteristik Responden Berdasarkan Status Pekerjaan}

Jumlah responden terbanyak dengan status karyawan kontrak (87\%)

\section{Uji Bivariat}

Dari hasil uji bivariate ditentukan interval penilaian dengan kategori mulai dari sangat rendah sampai sangat kuat. Untuk variabel kompensasi responden memiliki skor rata-rata berada di interval dengan kategori kuat. Hal ini menggambarkan tingginya hubungan factor kompensasi responden terhadap disiplin kerja. Untuk variabel motivasi kerja memiliki skor rata- 
rata berada di interval dengan kategori sedang untuk variabel karakteristik individu memiliki skor rata-rata berada di interval dengan kategori rendah, hal ini menggambarkan bahwa tingkat hubungan motivasi kerja dan karakteristik individu kurang kuat hubungannya dengan disiplin kerja dibandingkan dengan variable kompensasi.

\section{Uji Multivariat (Analisis Regresi Linier Berganda)}

Uji multivariate untuk mengetahui seberapa besar pengaruh variable bebas yang terdiri dari motivasi kerja (X1), karakteristik individu (X2), dan kompensasi (X3) terhadap variable terikat yaitu disiplin kerja $(Y)$. Hasil uji multivariate ketiga variable didapatkan memiliki pengaruh jika diregresikan secara bersamasama terhadap disiplin kerja. Untuk variable motivasi kerja dengan hasil nilai Beta 0,406; variable karakteristik individu dengan nilai Beta 0,546; dan variabel kompensasi nilai Beta 0,229 sehingga variable bebas yang paling memberikan dominan berpengaruh terhadap variable disiplin kerja adalah karakteristik individu, diikuti dengan variable motivasi dan terakhir adalah variable kompensasi.

\section{Uji Normalitas}

Pada uji normalitas pennulis menggunakan metode "Normal P-P Plot" dengan kriteria normalitas dapat dideteksi dengan melihat penyebaran data (titik) pada sumbu diagonal grafik atau dengan melihat histogram dari residualnya. Sehingga dari data didapatkan kesimpulan bahwa data terdistribusi secara normal.

\section{Uji Bivariat}

Dari uji korelasi yang mengacu pada nilai Pearson correlation, hubungan antara motivasi kerja dengan disiplin kerja memiliki korelasi sedang (nilai 0,583), hubungan antara karakteristik individu dengan disiplin kerja memiliki korelasi rendah (nilai 0, 388) dan hubungan kompensasi dengan disiplin kerja memiliki korelasi kuat (nilai 0, 608).

\section{Uji Multivariat}

Dengan Analisis Regresi Berganda diketahui bahwa variable motivasi kerja, karakteristik individu dan kompensasi samasama berpengaruh terhadap disiplin kerja, tetapi varaiabel yang paling dominan mempengaruhi disiplin kerja adalah variable karakteristik individu (nilai Beta 0,546), diikuti dengan variable motivasi kerja (nilai Beta 0, 406) dan terakhir variable kompensasi (nilai Beta 0,229).

\section{Uji Hipotesis}

\begin{tabular}{|c|c|c|c|c|c|c|}
\hline \multicolumn{7}{|c|}{ Coefficients $^{a}$} \\
\hline & & Unstan & Doefficients & $\begin{array}{l}\text { Standardi } \\
\text { Coefficie }\end{array}$ & & \\
\hline \multicolumn{2}{|c|}{ Model } & B & Std. Error & Beta & $\mathrm{t}$ & Sig. \\
\hline \multirow[t]{4}{*}{1} & (Constant) & -15.637 & 4.260 & & -3.671 & .001 \\
\hline & Karakteristik Responden & .546 & .161 & .402 & 3.383 & .002 \\
\hline & Motivasi & .406 & .113 & .473 & 3.600 & .001 \\
\hline & Kompensasi & .229 & .084 & .358 & 2.725 & .011 \\
\hline
\end{tabular}

a. Dependent Variable: Disiplin Kerja

Hasil pengujian hipotesis;

1. Sig $0,002<0,05$ dan T hitung $3,383<2,048$ (t tabel), Ho ditolak dan Ha diterima berarti karakteristik individu memiliki pengaruh signifikan terhadap disiplin kerja.

2. Sig $0,011<0,05$ dan T hitung $2,725>2,048$ (t tabel), Ho ditolak dan Ha diterima berarti kompensasi memiliki pengaruh signifikan terhadap disiplin kerja.

3. Sig $0,001<0,05$ dan $T$ hitung $3,600>2,048$ (t tabel), Ho ditolak dan Ha diterima berarti motivasi kerja memiliki pengaruh signifikan terhadap disiplin kerja.

\section{Identitas Responden}

Jumlah perawat di RS Cikunir Bekasi lebih banyak perempuan, dan mayoritas berusia $>26$ 30 tahun dengan lama bekerja 6 bulan -1 tahun tahun. Pendidikan terbanyak adalah D III dengan status pekerjaan mayoritas karyawan kontrak. Melihat rata-rata usia karyawan di RS Cikunir
Bekasi paling banyak berada pada usia yang produktif dengan masa kerja 6 bulan- 1 tahun yang bisa dikatakan masih memiliki pengalaman kerja yang rendah. Dengan demikian RS pelu mengatasi hal tersebut dengan diadakannya pelatihan internal maupun eksternal perawat dan dapat juga meningkatkan jenjang karir perawat di RS Cikunir Bekasi sehingga memiliki banyak peluang dalam hal pengembangan pelayanan serta memiliki tingkat pengetahuan dalam penyesuaian dengan adanya perubahan dalam lingkungannya.

Dari hasil analisa dapat dilihat bahwa semua variable bebas yaitu motivasi kerja, karakteristik individu dan kompensasi berpengaruh terhadap variable terikat yaitu disiplin kerja. Pengaruh yang diberikan ketiga variable bebas tersebut bersifat positif artinya semakin tinggi kompensasi, motivasi kerja dan karakteristik individu maka mengakibatkan semakin tinggi pula disiplin kerja yang 
dihasilkan. Variable karakteristik individu memiliki hubungan korelasi dengan disiplin kerja dan mempunyai pengaruh paling dominan diantara variable lainnya dengan nilai Beta 0,546. Hal ini dihubungkan dengan sebagian besar perawat berada pada usia produktif tetapi masih emiliki pengalaman kerja yang rendah. Sehingga perlu diberikan pelatihan internal ataupun eksternal di RS Cikunir. Untuk motivasi kerja dan kompensasi juga mempunyai hubungan positif dan pengaruh yang signifikan terhadap disiplin kerja. Dimana kompensasi memiliki arti penting karena mencerminkan upaya organisasi dalam mempertahankan dan meningkatkan kesejahteraan karyawan dimana jika karyawan merasa adil dan sejahtera akan meningkatkan disiplin Untuk variable kompensaasi perawat dengan pemberian imbalan atau jasa sesuai dengan beban kerja yang dimiliki dapat meningkatkan kesejahteraan perawat Begitu juga dengan motivasi, semakin tinggi insentif yang diterima akan meningkatkan motivasi kerja karyawan sehingga disiplin kerja juga meningkat.

Dari hal ini peneliti melihat bahwa masih adanya ketenagaan yang kurang sehingga karyawan mengeluhkan beban kerja yang lebih banyak. Disamping itu juga masih ada karyawan yang belum paham dengan salary yang standar dan belum ada penjelasan lebih terperinci tentang penggajian dari atasan. Dan untuk meningkatkan motivasi para perawat perlu diberikan pelatihan-pelatihan di unit-unit khusus agar dapat meningkatkan mutu pelayan rumah sakit. Dalam system penilaian kinerja dan disiplin kerja sudah dilakukan oleh RS dengan menggunakan sisitem dimana karyawan melakukan penilaian diri sendiri secara berjenjang kemudian dinilai olehpenanggung jawab unit dan dilanjutkan dengan manjer/ Ka. Bidang dan diteruskan ke direktur sehingga dapat diambil rata-ratanya. Namun karyawan masih belum memahami dengan baik tentang juknis pengisisannya. Dengan adanya dimensidimensi diatas maka peneliti melihat bahwa variable kepemimpinan juga perlu diperhatikan dan lebih dijadikan focus oelh rumah sakit sehingga bila rumah sakit berfokus pada variable yang memberikan hubungan signifikan maka disiplin kerja karyawan akan meningkat di RS Cikunir.

\section{SIMPULAN}

Dari hasil penelitian ini berarti motivasi kerja, karakteristik individu dan kompensasi memiliki hubungan dan berpengaruh signifikan dengan disiplin kerja perawat. Dimana dari ketiga variable yang paling dominan berpengaruh terhadap disiplin kerja yaitu variable karakteristik individu, sehingga $R S$ Cikunir Bekasi harus memfokuskan pada varaiabel karakteristik individu untuk dapat meningkatkan disiplin kerja.

Saran untuk RS Putera Bahagia:

1. Untuk manajemen RS, berusaha meningkatkan disiplin kerja perawat dengan memperbaiki faktor-faktor yang mempengaruhi disiplin kerja seperti penilaian disiplin kerja, kompensasi, hubungan baik karyawan, menerapkan jenjang karir, memberikan kesempatan untuk pendidikan dan pelatihan serta memberikan fasilitas pendukung sesuai dengan standar keselamatan pasien.

2. Untuk Divisi Keperawatan, membuat penyusunan pola ketenagaan yang sesuai dengan kualifikasi perawat, membuat jenjang karir perawat yang jelas, melakukan penilaian disiplin kerja sesuai dengan SOP dan kebijakan dari RS Cikunir dan melakukan sosialisasi tentang kebijakan-kebijakan tersebut.

3. Untuk Divisi Sumber Daya Manusia, melakukan sosialisasi tehadap struktur organisasi, system penilaian disiplin kerja, kompensasi terkait profesi perawat, melakukan monitoring dan evaluasi setiap bulan terhadap penilaian disiplin kerja perawat dan mengkoordinir pelaksanaan pelatihan baik internal maupun eksternal.

4. Untuk Tenaga Perawat, melaksanakan dan menjalankan system penilaian disiplin kerja yang terdiri dari penilaian kehadiran, jam kerja dan tata tertib perawat sehingga $\mathrm{RS}$ dapat mengupayakan pemberian reward kepada perawat yang memiliki disiplin tinggi ataupun memberikan punishment kepada perawat yang berdisiplin rendah.

\section{DAFTAR PUSTAKA}

A.A. Gede Kresnayana Pramana. I Nyoman Sudharma (2010) Pengaruh Kompensasi, Lingkungan Kerja Fisik dan Gaya Kepemimpinan terhadap Kinerja Karyawan pada LPD Desa Adat Jimbaran.

Aditama, TY. 2000. Manajemen Administrasi Rumah Sakit. UI Press. Jakarta

Ardiani, Herlin Kurniawati. 2003. Hubungan Antara Karakteristik Indivisu, Karakteristik Pekerjaan Dan Karakteristik Lingkungan Pekerjaan Dengan Motivasi Kerja Perawat Di Unit Rawat Inap RS Haji Jakarta. Skripsi. UI

Aries Susanty, Sigit Wahyu Baskoro J@TI UNDIP, Volume VII, No 2, Mei 2012

Astuti, Nurul Dwi.2010. Hubungan Motivasi Kerja Dengan Disiplin Kerja Pada Pegawai Non Medis RS. Kanker Dharmais. Skripsi. UI

Budiyanto, 2006. Analisis Hubungan Antara Motivasi dan Kemampuan Kerja Perawat Dengan Kualitas Pelayanan Kesehatan Pada RSUD Tarakan. Skripsi. Jakarta 
Dannie Gunawan, Mukhlis Yunus, Amri Jurnal Manajemen ISSN 2302-0199 Pasca Sarjana Universitas Syiah Kuala Volume 2, No. 1, November 2013

Djajoesman, S. 1996. Faktor - Faktor yang Berhubungan dengan Motivasi Kerja Perawat di Pavilium Khusus Swasta RS Cipto Mangunkusumo Jakarta. Tesis. UI

Fatimah, 2007. Hubungan otivasi Kinerja Dengan Kepuasan Kerja Karyawan Di RS Mohammad Thamrin Cilengusi. Tesis. UI

Fatmawati, Mahdani, Sofyan Idris. Jurnal Manajemen ISSN 2302-0199 Pascasarjana Universitas Syiah Kuala. Volume 1, No. 1, Agustus 2012

Firiyana. 2003. Faktor - Faktor yang Berhubungan dengan Disiplin Waktu Kerja Perawat RS. Pelni Petamburan. Skripsi. UI

Ghozali, Imam. 2005. Aplikasi Analisis Multivariate dengan Program SPSS. Semarang: BP Universitas Diponegoro. Semarang.

Guritno, Bambang dan Waridin. 2005. Pengaruh Persepsi Pegawai Mengenai Perilaku Kepemimpinan, Kepuasan Kerja Dan Motivasi Terhadap Kinerja. JRBI. Vol 1. No 1. Hal: 63-74.

Hasibuan, M.S.P. 2003, Organisasi dan Motivasi Dasar Peningkatan Produktifitas, Jakarta : Bumi Aksara

Jurnal Manajemen Bisnis STIE IBBI ISSN 18583199

Malthis, R.L dan Jackson. 2001. Manajemen Sumber Daya Manusia. Salemba Empat. Jakarta

Mangkuprawira, Sjafri dan Aida Vitayala Hubeis. 2007. Manajemen Mutu Sumber Daya Manusia. Cetakan Pertama. Ghalia Indonesia. Bogor

Mondy,R. Wayne Mondy. Manajemen Sumber Daya Manusia. Edisi 10. Jilid 1

Prasojo, Sigit. 2005. Hubungan Karakteristik dan Motivasi dengan Disiplin Kerja Perawat Pelaksana di Ruang Rawat Inap RSUD Batang, Ttesis. UI

Robbins, Stephen. P. dan Mary Coulter. 2005. Manajemen. Gramedia. Jakarta.

Soedjono. 2005. "Pengaruh Budaya Organisasi terhadap Kinerja Organisasi dan Kepuasan Kerja Karyawan pada Terminal Penumpang Umum di Surabaya". Jurnal Manajemen \& Kewirausahaan. Vol. 7, No. 1, Maret

2005: 22-47.

Sukamto, Edi. 2005. Analisis Beban Kerja Dan Faktor - Faktor Yang Berhubungan Dengan Disiplin Kerja Perawat Pelaksana Di Rungan Inap Rumah Sakit Islam Samarinda. Tesis. UI
Sutrisno, Edy., 2009. Manajemen Sumber Daya Manusia Edisi Pertama, Kencana Prenamedia Group .

Suranto (surantokppnbangko@gmail.com) Jurnal Organisasi dan Manajemen, Pengaruh Motivasi, Gaya Kepemimpinan dan Disiplin Kerja terhadap Kinerja Pegawai pada KPPN Percontohan Jambi, Bangko dan Muara p Bungo, Volume 10, Nomor 2, September 2014,148-160

Sugiyono. 2007. Statistik Untuk Penelitian. Bandung : CV. Alfabeta

Widodo, 2017. "Metodologi Penelitian Populer \& Praktis. Ed.1, Ceta.1, Jakarta: Rajawali Pers. Xxiv,302 hlm. 